\title{
Survey Techniques for Freshwater Streams on Oceanic Islands: Important Design Considerations for the PABITRA Project ${ }^{1}$
}

\author{
7. E. Parbam ${ }^{2}$
}

\begin{abstract}
Fundamental differences in life history patterns of most indigenous freshwater stream species on oceanic islands and freshwater species in continental stream systems require important differences in design of appropriate aquatic survey methodologies. As an example of these issues, use of Instream Flow Incremental Methodology (IFIM) and the Index of Biotic Integrity (IBI) for describing island stream conditions are examined. Designed mainly for identifying optimal flow for salmonid fishes in the western United States, IFIM is difficult to apply to Hawaiian streams because of frequent flash floods in the Islands and because of the inherent difficulty of relating observed fish densities to total usable habitat in island streams. IBIs have been applied widely on the United States mainland as a technique for determining the health of a stream and aiding in stream fish conservation and management. Recently, there has been an attempt to establish an IBI for Hawaiian streams. Application of this technique to oceanic island streams raises a number of serious questions about the IBI's validity for use in Hawaiian streams. Potential problems are inherent in the basic assumptions of the IBI. They result in unintended consequences when applied to oceanic island streams; examples include erroneously attributing naturally occurring differences in observed fish assemblages to human-induced environmental change, not accommodating differences in closed and open system dynamics linked to life cycles of indigenous stream species, and not understanding implications of low-diversity environments typical of remote oceanic islands. Past research on Hawaiian streams supports use of appropriate survey and analysis techniques such as those developed for the Pacific-Asia Biodiversity Transect (PABITRA) for use among islands of the tropical Pacific.
\end{abstract}

The focus of the Pacific-Asia Biodiversity Transect (PABITRA) network has been the development of comparisons both horizontally and vertically within and among islands

${ }^{1}$ This research was supported by a grant from the Division of Aquatic Resources and Commission on Water Resource Management, Department of Land and Natural Resources, State of Hawai'i, for research on Hawaiian stream fishes via the Research Corporation of the University of Hawai'i and the U.S. Fish and Wildlife Service Sport Fish Restoration Program, Grant Agreement No. F-14-R. Manuscript accepted 16 April 2004.

${ }^{2}$ School of Natural Resource Sciences, University of Nebraska, Lincoln, Nebraska 68583-0759 (jparham2@ unl.edu).

Pacific Science (2005), vol. 59, no. 2:283-291

(C) 2005 by University of Hawai'i Press

All rights reserved of the tropical Pacific Ocean. The upland forests of volcanic high islands hold much of the remaining natural terrestrial biodiversity. In addition to its important role as a reservoir of native biodiversity, the upland forest also provides the catchment area for the island streams that flow downward from islands' peaks. These island streams form an integral component of the island ecosystem. Perennial streams drain the wet montane forests of surface and subsurface water originating principally from the orographic rains near the peaks of islands. These streams typically flow clear and cool down a steep streambed, pass through the flatter lowlands, and mix with ocean water in short estuarine areas. Although the geomorphology of the streams on oceanic high islands may be viewed as spatially compressed examples of continental streams, the ecology of indigenous stream an- 
imals, the hydrology of the streams, and the tight linkage between the streams and ocean result in an ecosystem far from analogous to the ecosystems of most continental streams.

\section{Stream Animals}

Nearly 30 families of fishes occur frequently in freshwater streams on oceanic islands of the subtropical and tropical Pacific, but only four (Anguillidae, Eleotridae, Gobiidae, and Kuhliidae) include indigenous species mostly limited to fresh water as adults (Fitzsimons et al. 2002). Among the latter group, the families Gobiidae and Eleotridae are ascendant with respect to numbers of species and their almost ubiquitous distribution among island streams in the Pacific and elsewhere in the world's Tropics and subtropics (Fitzsimons et al. 1996). These animals are diadromous or, more specifically, amphidromous (McDowall 1993, 1997). Adults spawn in fresh water, and their eggs hatch within about $48 \mathrm{hr}$. Free-swimming embryos (sensu Balon 1990) are washed out to sea where they remain in the plankton until returning to freshwater streams as larvae or recently transformed postlarvae. As in other types of diadromy, amphidromy includes two migrations, but there is no reproductive event immediately following either migration. Genetic information for Hawaiian stream fishes (Fitzsimons et al. 1990, Zink et al. 1996, Chubb et al. 1998) does not indicate homing to natal streams or even islands; individuals from the five species occurring throughout the chain of high islands are generally indistinguishable. The larger invertebrates (two species of crustaceans and two mollusks) are also amphidromous. Presumably, the period of time spent in the ocean is long enough for individuals of amphidromous species to be distributed throughout the high islands with sufficient frequency to prevent isolation and differentiation. As a direct effect of their amphidromous life cycle, every indigenous fish, shrimp, prawn, or limpet in a Hawaiian stream is a migrant. Thus, the adults in a stream may or may not have begun life in that stream, and the young animals observed near them are not necessarily their offspring.

\section{Flash Floods}

In addition to aquatic animals sharing an amphidromous life cycle, the spatial compression of the geomorphology of the stream system and the prevailing weather patterns combine to cause distinctive hydrological conditions in island streams. Localized orographic rain and the passage of strong weather fronts produce flash floods that wash silt, sand, leaf litter, and other debris downstream and into the ocean. The rising and falling of a flood pulse may take weeks to many months in large continental river systems, but in the majority of island streams the flood pulse passes from the streams headwaters into the ocean within a few days. Flash floods (freshets) can occur at any time of the year but are usually most frequent during the rainy season (roughly May through August) in the Southwest Pacific and during winter months (February through April) above the equator (Fitzsimons et al. 2002). In Hawai' $i$, freshets are common. It has been argued by Fitzsimons and Nishimoto (1997) that a typical Hawaiian stream is always in a state of recovery from the most recent flash flood. These freshets present indigenous animals in island streams with episodic environmental changes that would be considered disastrous in a continental stream. However, freshets in island streams are usually beneficial rather than deleterious. Stream animals are well adapted for holding station during freshets, the periodic flushing decreases silt deposited on benthic eggs, and high flow events widen and deepen stream mouths where animals migrate into and out of the sea. Even if it could be accomplished, establishing a year-round uniform flow in an island stream would have an effect on stream animals that could be just as ecologically disruptive as would frequent flash floods in most continental streams. Island streams are not stable; they are constantly changing.

\section{Amphidromy}

Another dynamic of island streams that separates these streams from their continental counterparts is the tight and important link- 
age between freshwater streams and marine systems (McDowall 1998). As a result of the differences in physical size when comparing most continental stream systems with island stream systems, a strict consideration of complete connectivity within the continental stream network is not always necessary. In continental streams, a stream section with relatively consistent geomorphology and instream conditions may exist for many kilometers, and the populations of freshwater fishes may exist for many generations within this section of suitable stream habitat. In contrast, the amphidromous nature of island fishes and macroinvertebrates requires two intragenerational migratory events (i.e., the downstream movement of free-swimming embryos into the ocean and the upstream movement of postlarvae back to suitable adult habitats). The description of an island stream ecosystem must include the stream in question, its estuary, the ocean, and, also important, a group of other streams that may contribute to the stream's pool of available larval recruits.

\section{PABITRA Aquatic Surveys}

This discontinuity between stream conditions and the life history patterns of island stream animals with those of typical continental streams is the basis for the important underlying design considerations of the aquatic surveys presented in the PABRITRA manual for biodiversity assessment (tentatively scheduled for publication in 2005; http://www.botany .hawaii.edu/pabitra). In addition to an explicit consideration of the amphidromous life history requirements, the surveys were designed to allow coordinated integration of the data into island stream ecosystem models that view ecosystem functions as a series of nested spatial scales (Parham 2002). In this paper I report on the important design considerations that were developed into the PABITRA aquatic survey methodology, describe how the survey data can be used to answer important questions facing island stream ecologists, and compare and contrast the basic assumptions and goals of the methodology with two common continental stream models, the Instream Flow Incremental Methodology (IFIM) and the Index of Biotic Integrity (IBI).

\section{DISCUSSION}

\section{Important Design Considerations}

Fundamental to the design of any survey methodology aimed at understanding an ecosystem is the need to encompass the spatial extent of the the populations of major organisms. In the case of oceanic island streams, the primary organisms of concern are the amphidromous fishes and macroinvertebrates. From small-scale spatial processes such as occupancy of suitable microhabitats to largescale events such as spawning migrations, the relevant spatial context for these organisms is not static; therefore, survey methodologies need to be carefully considered.

The design of the aquatic survey methodology reviewed here was based upon prior field experience in Hawai $i$ and Micronesia and the desire to allow the survey information to account for the different spatial scales important to the amphidromous animals. To accomplish this goal, the surveys were designed to be integrated with a series of habitat models based on a nested spatial hierarchy (Parham 2002). The nested hierarchy for island streams considers a number of different scales, including the site, reach, stream, island, and island chain spatial scales. Different sections of the aquatic surveys focus on different aspects of the amphidromous animals' ecology and the expression of their ecology at the various spatial scales. By considering the different spatial scales, variation observed at one scale will not be attributed incorrectly to only that scale. An example of this situation deals with the observed absence of a species from an individual site within a stream. The species may be absent as the result of unsuitable microhabitat conditions (a site-level effect), or the species may not be able to pass a downstream barrier (a stream-level effect), or recruitment of this species may have failed in several streams that contribute to the local population (an island effect). By concluding that the local site conditions were unsuitable 
as a result of the site-specific observation, the researcher may have incorrectly diagnosed the actual reason for the absence of the species. This example highlights the need for the consideration of multiple spatial scales when attempting to understand the dynamics of an island stream and its amphidromous biota.

In spite of the issues of multiple spatial scales of observation, drastic but natural changes in water flow, and the movement of aquatic animals' life stages between stream and ocean during their life histories, the answers to a combination of questions can be used to determine the condition of an island stream:

1. Is microhabitat use by adult fishes and macroinvertebrates consistent with that observed in other island streams? Microhabitat variables such as depth, velocity, substrate, and others are recorded randomly throughout a stream and at the specific location of stream animals. Microhabitat use information is attributed to the site-level spatial scale.

2. Does the instream distribution of adult fishes and macroinvertebrates parallel that observed in other island streams? The instream distribution of adults is determined from instream observations using the point quadrat method developed by Robert Nishimoto (Hawai'i Division of Aquatic Resources) for surveying Hawaiian stream animals (Baker and Foster 1992). Use of this standardized method allows survey information collected in one stream to be compared with data from other streams. Surveys of instream distribution are attributed to the reach- and stream-level spatial scales.

3. Are the major species of stream animals reproducing? Reproduction in stream animals is documented by the presence of eggs, newly hatched larvae, and gravid females; by underwater observations of the prespawning behavior of courting males and females; and occasionally by actual spawning. In addition to direct observation of spawning be- havior, capture of the drifting freeswimming embryos with a fine-meshed net near the stream mouth can provide information regarding the type of species reproducing and the extent of their contribution to the overall output of larvae from the stream. These observations of reproduction are attributed to the site- or stream-level spatial scale.

4. Do the patterns of recruiting fish and invertebrate larvae from the ocean into fresh water coincide with those known for other island streams? A Breder trap using mesh wings as modified by Darrell Kuamo'o (Hawai'i Division of Aquatic Resources) specifically for use in island streams is ideal for determining the presence and relative quantity of larval fishes and invertebrates migrating from the sea during a 24-hr period. As with most activities of stream animals, there is conspicuous speciesspecific periodicity in regard to the timing of migration events (Nishimoto and Kuamo'o 1997). The capture of recruiting animals is a subset of all of the larvae in the nearby ocean waters and is attributed to the island-level spatial scale.

5. What are the current conditions of the stream and surrounding riparian area during the survey period? Measurements and visual descriptions of the stream's flow, habitat distribution, and riparian conditions are recorded to allow the changes in the site to be observed over repeated samples. The stream's conditions are attributed to the site- and reach-level spatial scales.

6. What, if any, are the introduced species and what is their microhabitat use and instream distribution? It is important to determine the distribution of introduced fishes because of their potential interactions with the native fishes. For example, low flow conditions may increase niche overlap between exotic and native fishes (McRae 2002) and might lead to competitive interactions and enhanced transmission of parasites that are detrimental to native fishes 
(Font and Fitzsimons 1997). Sampling to compare the relative densities and distribution of exotic fishes and to determine parasitic infections in exotic and native fishes is used to gauge stream conditions. This information can be attributed to the site-, reach-, and streamlevel spatial scales.

Equally important to the ecologically based series of survey questions is the need for an accurate description of the physical watershed and stream channel morphology. Recent advances in remote sensing and Geographic Information System (GIS) technologies make the delineation of the stream's watershed and the description of stream habitats a practical task. By comparing numerous island streams, a geomorphological classification system can be developed (Parham 2002). Appropriate classification is important because aquatic animals are distributed in species-specific patterns along the lengths of island streams. Gobies have a sucking disk formed from fusion of the pelvic fins. In many amphidromous species, such as the $\mathrm{Ha}$ waiian Lentipes concolor, Sicyopterus stimpsoni, and Awaous guamensis, the structure is used as a holdfast that permits the animals to cling to rocks in swift water while feeding or working their way upstream. Other species may lack this structure (eleotrids) or it may be insufficiently rigid and muscled to allow climbing (e.g., Stenogobius hawaiiensis). In Hawai' $\mathrm{i}$, Eleotris sandwicensis and S. hawaiiensis are common in the lower reaches of streams where the current is reduced. A waterfall of a meter or more usually prevents these species from moving farther inland. In contrast, the three upstream species often climb waterfalls and move through riffles while moving upstream. Awaous guamensis and S. stimpsoni are common above waterfalls $10-20 \mathrm{~m}$ in height, and $L$. concolor has been found above waterfalls exceeding $350 \mathrm{~m}$. In a stream that ends with a high waterfall dropping directly onto the beach, $L$. concolor is likely to be the only species present. In a stream terminating in a moderately high waterfall or in a highgradient stream with swift water entering the sea, L. concolor, A. guamensis, and S. stimpsoni are likely to be seen, but $E$. sandwicensis and
S. bawaiiensis probably will not. Finally, in a low-gradient stream and especially one with a very long estuary, E. sandwicensis, S. hawaiiensis, and perhaps $A$. guamensis may be the only resident fishes. Macroinvertebrates in Hawaiian streams also exhibit similar instream distributions by species. Although there are many more species of aquatic animals in streams of western Pacific islands than in Hawai'i (Fitzsimons et al. 2002), species-specificity in their distribution along the length of a stream is characteristic (Parham 1995, Nelson et al. 1997). The physical shape of the stream course controls the observed instream distribution of stream animals, and comparisons between populations should be restricted to a comparison of similar streams.

\section{Comparisons with the Instream Flow Incremental Methodology}

To reduce the harm caused to stream organisms by decreases in water flow, the link between instream habitat and the level of stream discharge has been extensively studied. The development of IFIM and Physical Habitat Simulations (PHABSIM) are direct outgrowths of the need for the synthesis of fish ecology and water resource management. The extensive use of these procedures to determine instream flow standards attests to the need for quantitative descriptions of this linkage. The IFIM was developed to determine the relationship between the area of usable fish habitat and stream discharge (Bovee and Cochnauer 1977). It is actually inaccurate to call IFIM an aquatic survey method, and, therefore, the comparison of these two techniques is somewhat misleading. Although the goals of the techniques are not strictly comparable, the widespread application of the IFIM approach makes the comparison between the PABITRA methodology and IFIM useful.

IFIM was developed in response to water diversions that created low flow conditions that limited available trout habitat in the streams and rivers of the western United States. By applying appropriate components of IFIM, a biologist could determine the area 
of the major microhabitat factors (depth, velocity, and substrate) and their change as increments of water were added or removed from the stream. This methodology proved to be a valuable tool in the advancement of instream flow policy and has been applied to many situations and improved by further refinements. IFIM is considered a decision support mechanism that takes into account the micro- and mesohabitats and the water quality of the stream (Bovee et al. 1998).

With the apparent success of the technique and the widespread diversion of surface waters on oceanic high islands, there seems to be a straightforward utility of IFIM in island streams. The practicality of IFIM was assessed for streams in Hawaici and was concluded to be suitable under certain conditions, with a number of important caveats (Kinzie et al. 1986). One important result from Kinzie et al. (1986) was that habitatutilization curves were found to be nontransferable between streams. This outcome is semicontradictory to other studies that suggest predictable patterns of microhabitat use and instream distributions for island stream fishes (Kinzie 1988, Brasher 1997, Nelson et al. 1997, Fitzsimons et al. 2002, Parham 2002). These contradictory views on habitat use by island stream fishes may result from independent underlying issues. First, differences in the hydrology and geomorphology between study streams introduce variations in habitat availability not accounted for in the study. Second, because of their oceanic larval phase, observed populations of island stream fishes reflect recruitment success, connectivity with the ocean, and habitat suitability. As a result, the assumption of close correlation between total usable habitat and the standing crop of fish may not be valid, and the application of IFIM in island streams will require additional modeling techniques not required in most continental stream situations.

\section{Comparisons with the Index of Biotic Integrity}

The IBI has been applied widely for determining the health of a stream and has extensive supporting literature to show its applicability to continental stream systems (Karr 1981, 1991, Barbour et al. 1991). Like any method, IBI has strengths and weaknesses, many resulting from the technique's underlying assumptions. IBI was originally developed for warm-water streams in Illinois and has since been expanded to many other streams across the United States. As with IFIM, the differences in the ecology of amphidromous fishes in island streams and freshwater fishes in continental streams create problems with the application of IBI to island streams. Although this discussion is not intended to be a full critique of the use of IBI in island streams, a couple of problems will be discussed. These problems revolve around the lack of spatial scale control within the IBI and problems that can occur within Hawaiian streams that are not as important within the larger continental stream systems.

An assumption and one of the main goals of the IBI is to attribute observed site conditions with past and current local effects. The IBI's metrics are intended to be sensitive to changes in the local water quality. The assumption is that the biota is a continuous sampler of the quality of water within a stream section, and that a pollution event, even if not measured by humans, will be felt by the aquatic community (Karr et al. 1986). In the continental stream situation, the measured differences between IBI scores are expected to accurately reflect the changes in the water quality of the stream at or upstream of the survey section. Because the majority of continental fishes are true freshwater fishes and the adult fishes and their offspring should be observed in relatively close proximity, changes in community membership are considered a direct response to environmental disturbance (usually anthropogenic). This situation contrasts sharply to the island ecosystem. Most island fishes are migratory, and the adults observed within a stream are not necessarily related to young fishes within the stream. If the shift in community membership is related to recruitment (either in the ocean or due to a downstream barrier) and not water quality, then the assumption linking community membership to water quality is invalid. This problem has been reported 
elsewhere: "In freshwater fish faunas with a high proportion of migratory species, as in New Zealand, these changes in occurrence and abundance result in a breakdown of the relationship between fish abundance and habitat quality, making application of the index of biotic integrity (IBI) as a measure of habitat quality problematical since the index depends on the relationship between population metrics and habitat quality" (McDowall and Taylor 2000:357).

The IBI assumes a closed system concept, which is valid for most continental stream fishes. In contrast, processes controlling amphidromous stream fishes are described within an open system concept. Because the effective population size for amphidromous fishes may encompass a number of streams, the observed adults within a certain stream may not be the result of successful spawning within that stream. For example, a stream in a "sink condition" may score high on the IBI (many adult fishes) but low on habitat and in reality contributes little to the overall population. In contrast to this situation, a stream in a "source condition" could have fewer adults (low IBI), but their larval production is critical for the maintenance of other streams' populations. In these two examples, the sink stream is of lower importance to the population dynamics than the source stream, but the IBI results in the opposite conclusion. Overall, major differences in the life history of diadromous stream fishes from that of continental stream fishes make the transfer of commonly used and well-supported stream survey and model methodologies difficult or inappropriate.

\section{CONCLUSIONS}

The methodology for aquatic surveys presented in the PABITRA manual for biodiversity assessment (http//:www.botany.hawaii .edu/pabitra) is intentionally linked with the development of multispatial stream ecosystem models. Both the field methodology and the multispatial models are flexible and allow the consideration of multiple factors concerning the amphidromous biota. By allowing the survey information to be segregated into its ap- propriate spatial scale, the conclusions drawn from the information will not overextend their realistic bounds. In addition, as survey techniques improve and expand throughout an island system, ecologically sensible data integration can occur. The coordination of data in the nested hierarchy allows different needs to be accommodated and multiple users to survey streams, store data, and query the database for their individual purposes. More technically difficult questions concerning larval drift or source/sink dynamics can be addressed as data on additional streams throughout the islands are gathered.

In the future, a spatially nested hierarchy will allow the lateral expansion of the stream models to interface with models of terrestrial watershed functions, including vegetation patterns, and surface and groundwater hydrology. The seaward extension of the stream models is also recommended and would provide an increased understanding of the interaction of streams with their estuaries, nearshore marine areas, and openocean dynamics. All these potential linkages are consistent with the overall goals of the PABITRA project in its plans to understand the vertical and horizontal patterns within and among island ecosystems.

\section{ACKNOWLEDGMENTS}

I thank J. Michael Fitzsimons for discussions on and review of the manuscript, and William Devick, Robert Nishimoto, Glenn Higashi, and Darrell Kuamo'o of Hawai'i Division of Aquatic Resources for their extensive help and support of stream research. Additional thanks to Dieter Mueller-Dombois for his effort in the development of the PABITRA network and the organization of the symposium at the 20th Pacific Science Congress at which this paper was presented.

\section{Literature Cited}

Baker, J. A., and S. A. Foster. 1992. Estimating density and abundance of endemic fishes in Hawaiian streams. Department of Land and Natural Resources, Division 
of Aquatic Resources, State of Hawai'i, Honolulu.

Balon, E. K. 1990. Epigenesis of an epigeneticist: The development of some alternative concepts on the early ontogeny and evolution of fishes. Guelph Ichthyol. Rev. 1:1-42.

Barbour, M. T., J. B. Stribling, and J. R. Karr. 1991. Biological criteria: Streams-4th draft. EPA Contract No. 68-CO-0093. U.S. Environmental Office of Science and Technology, Washington.

Bovee, K. D., and T. Cochnauer. 1977. Development and evaluation of weighted criteria, probability-of-use curves for instream flow. U.S. Fish and Wildlife Service Biological Service Program FWS/ OBS-77/63.

Bovee, K. D., B. L. Lamb, J. M. Bartholow, C. B. Stalnaker, J. G. Taylor, and J. Henriksen. 1998. Stream habitat analysis using the Instream Flow Incremental Methodology. Biological Resources Division Information and Technology Report USGS/ BRD-1998-0004.

Brasher, A. 1997. Habitat use by fish ('o'opu), snails (hihiwai), shrimp ('opae) and prawns in two streams on the island of Moloka'i. Technical Report 116. Cooperative $\mathrm{Na}$ tional Park Resources Studies Unit, University of Hawai'i at Mānoa, Honolulu.

Chubb, A. L., R. M. Zink, and J. M. Fitzsimons. 1998. Patterns of mtDNA variation in Hawaiian freshwater fishes: The phylogenetic consequences of amphidromy. J. Hered. 89:8-16.

Fitzsimons, J. M., and R. T. Nishimoto. 1997. Hawaiian stream and trout streams-an imperfect analogy. Pages 345-353 in W. S. Devick, ed. Proceedings of the 1996 Meetings of the Western Association of Fish and Wildlife Agents, Honolulu, Hawai'i. Hawai'i Division of Aquatic Resources, Honolulu.

Fitzsimons, J. M., R. M. Zink, and R. T. Nishimoto. 1990. Genetic variation in the Hawaiian stream goby, Lentipes concolor. Biochem. Syst. Ecol. 18:81-83.

Fitzsimons, J. M., R. T. Nishimoto, and W. S. Devick. 1996. Maintaining biodiversity in freshwater ecosystems on oceanic islands of the tropical Pacific. Chin. Biodiversity 4 (supplement): 23-27.

Fitzsimons, J. M., J. E. Parham, and R. T. Nishimoto. 2002. Similarities in behavioral ecology among amphidromous and catadromous fishes on the oceanic islands of Hawai'i and Guam. Environ. Biol. Fishes 65:123-129.

Font, W. F., and J. M. Fitzsimons. 1997. The role of parasitology research in fish conservation and management: A case study from Hawai'i. Pages 354-358 in W. S. Devick, ed. Proceedings of the 1996 Meetings of the Western Association of Fish and Wildlife Agents, Honolulu, Hawai'i. Hawai'i Division of Aquatic Resources, Honolulu.

Karr, J. R. 1981. Assessment of biotic integrity using fish communities. Fisheries (Bethesda) 6:21-27.

1991. Biological integrity: A long neglected aspect of water resources management. Ecol. Appl. 1:66-84.

Karr, J. R., K. D. Fausch, P. L. Angermeier, P. R. Yant, and I. J. Schlosser. 1986. Assessing biological integrity in running waters: A method and its rationale. Ill. Nat. Hist. Surv. Spec. Publ. 5.

Kinzie, R. A., III. 1988. Habitat utilization by Hawaiian stream fishes with reference to community structure in oceanic island streams. Environ. Biol. Fishes 22:179_ 192.

Kinzie, R. A., III, J. Ford, A. R. Yeun, and S. J. L. Chow. 1986. Habitat modeling of Hawaiian streams. Water Resources Center Technical Report 171, University of Hawai'i, Honolulu.

McDowall, R. M. 1993. Implication of diadromy for the structuring and modeling of riverine fish communities in New Zealand. N. Z. J. Mar. Freshwater Res. 27:453-462.

- 1997. Is there such a thing as amphidromy? Micronesica 30:3-14.

- 1998. Fighting the flow: Downstream-upstream linkages in the ecology of diadromous fish faunas in west coast New Zealand rivers. Freshwater Biol. 40:111-122.

McDowall, R. M. and M. J. Taylor. 2000. 
Environmental indicators of habitat quality in a migratory freshwater fish fauna. Environ. Manage. 25:357-374.

McRae, M. M. 2002. Microhabitat use in an assemblage of native and introduced stream fishes in Wailoa Stream, island of Hawai'i. M.S. thesis, Louisiana State University, Baton Rouge.

Nelson, S. G., J. E. Parham, R. B. Tibbatts, F. A. Camacho, T. Leberer, and B. D. Smith. 1997. Distributions and microhabitats of amphidromous gobies in the streams of Micronesia. Micronesica 30:83-91.

Nishimoto, R. T., and D. G. K. Kuamo'o.
1997. Recruitment of goby postlarvae into Hakalau Stream, Hawai'i Island. Micronesica 30:41-49.

Parham, J. E. 1995. Habitat use by an assemblage of oceanic island streamfishes. M.S. thesis, University of Guam, Mangilao.

- 2002. Spatial models of Hawaiian streams and stream fish habitats. Ph.D. diss., Louisiana State University, Baton Rouge.

Zink, R. M., J. M. Fitzsimons, D. L. Dittman, D. R. Reynolds, and R. T. Nishimoto. 1996. Evolutionary genetics of Hawaiian freshwater fish. Copeia 1996:330-335. 
